\title{
The Impact of COVID-19 quarantine on dietary habits and physical activity in Saudi Arabia: a cross- sectional study
}

\author{
Manar Abduljalil Bakhsh \\ King Abdulaziz University \\ Jomana Khawandanah \\ King Abdulaziz University \\ Rouba Khalil Naaman ( $\square$ rnaaman@kau.edu.sa ) \\ King Abdulaziz University \\ Shoug Alashmali \\ King Abdulaziz University
}

\section{Research Article}

Keywords: COVID-19, dietary habits, nutrition, physical activity, quarantine, weight change

Posted Date: November 10th, 2020

DOI: https://doi.org/10.21203/rs.3.rs-104354/v1

License: (c) (i) This work is licensed under a Creative Commons Attribution 4.0 International License.

Read Full License

Version of Record: A version of this preprint was published at BMC Public Health on July 30th, 2021. See the published version at https://doi.org/10.1186/s12889-021-11540-y. 


\section{Abstract}

Background: The COVID-19 pandemic has forced governments around the world to impose strict hygiene and national lockdown measures, which in turn has changed the dietary and lifestyle habits of the world's population. Thus, the aim of this study is to evaluate whether dietary and physical activity behaviors of Saudi Arabia's adult population changed during the COVID-19 quarantine.

Methods: An electronic questionnaire was distributed on social media between June and July 2020 and was completed by 2,255 participants ( $24 \%$ aged $30-39$ years old, $64 \%$ female, $68 \%$ university educated).

Results: Over $40 \%$ and $45 \%$ of participants reported eating and snacking more, respectively, which led to weight gain in $38 \%$. Most participants reported that they consumed home-cooked (73\%) and healthy meals $(47 \%)$, while only $7 \%$ reported that they consumed foods from restaurants. Feelings of boredom and emptiness (44\%) and the availability of time for preparing meals $(40 \%)$ were the main reasons for changing dietary habits. Honey (43\%) and vitamin C (50\%) were the most consumed immune-boosting food and dietary supplement, respectively. COVID-19 also had a negative impact on physical activity, lowering the practice in $52 \%$ subjects, which was associated with significant weight gain $(p<0.001)$.

Conclusion: Assessing the changes to the population's dietary habits and physical activity during the lockdown will help predict the outcome of the population's future health and wellbeing after the pandemic.

\section{Background}

The coronavirus disease, also known as COVID-19, is a serious acute respiratory syndrome generated by the new SARS coronavirus 2 (SARS-CoV-2), which has resulted in a spread of moderate to severe illness globally [1]. This disease was initially reported at the end of December 2019 with limited cases in Wuhan, China. Since then, COVID-19 has become a serious and rapidly emerging and evolving situation, spreading outside China and Asia [2-4]. In March 2020, the World Health Organization (WHO) declared COVID-19 a global pandemic and public health threat [5]. According to the organization's COVID-19 report released on July 28,2020 , the latest number of total confirmed cases and death worldwide are $16,341,920$ and 650,805 , respectively [6]. This rapid global spread of COVID-19 requires fast assessments and investigations at population level [7]; therefore, most governments have imposed lockdowns and restrictive guidelines in their countries [8].

In Saudi Arabia, the number of COVID-19 cases has been increasing since February 2020. The Saudi Ministry of Health has made enormous efforts and guidelines to eradicate the virus [9], and the government established specific lockdown precautions policies in March 2020: forcing individuals to quarantine themselves at home, suspending travel, imposing social distancing rules, and banning attendance at workplaces, schools, restaurants, shops, and gyms $[9,10]$. To date, Saudi Arabia has had around 268,934 confirmed cases and 2,760 deaths, which constitutes about $0.7 \%$ of the total population [11]. 
During quarantine, changes in health and socioeconomic status have been reported worldwide [12]. Other negative consequences related to the stay-at-home restrictions include anxiety, stress, depression, emotional eating (as well as other dietary changes), and limited physical activity in the adult population [13]. These consequences were accompanied with higher food intake, sleeping disorders, and weight changes [14]. Recent studies show that good hydration, good quality of sleep, planned daily physical activity, and a healthy balanced diet would help reduce stress during quarantine [15].

Nutritional status during the COVID-19 quarantine has been severely altered worldwide and become a priority in this stressful situation. Nutritional deficiencies of macronutrients and micronutrients are linked with suppressed immunity and increased infection susceptibility. Consuming supportive nutrients and antioxidants, such as zinc, iron, and vitamins $A, D, E$, and $C$ is essential for maintaining healthy immune system $[16,17]$. Although negative dietary habits during quarantine have been reported in several countries, such as Poland and Italy [18, 19], COVID-19 confinement has also led to healthy dietary behaviors in Spain, as reflected by high compliance to the Mediterranean diet. This improvement could play a positive role in preventing chronic diseases and COVID-19 related complications if persistent [20]. However, information related to the impact of the COVID-19 quarantine on dietary habits in Saudi Arabia is lacking.

Natural remedies comprise a huge part of Saudi Arabian traditions, with a great level of acceptability and popularity. The Saudi population is well known for their great reliance on natural products, such as lemon juice and honey, which are thought to boost the immune system, especially during critical conditions like COVID-19. A recent study from Saudi Arabia has proposed a novel nutritional treatment approach for COVID-19, suggesting the use of natural remedies like Nigella sativa and natural honey, which are known to have positive therapeutic immune and antiviral effects [21].

Physical activity is at a low level among the Saudi population [22] due to certain barriers, such as hot weather, poor transportation systems, and strict cultural beliefs in some parts of the country. Low levels of physical activity and sedentary lifestyle have been suggested for interaction and dysregulation of body fat and appetite response [23] and may contribute to an increase in obesity worldwide [24,25]. The WHO currently recommends that adults not diagnosed with COVID-19 or experiencing respiratory symptoms should perform at least 150 minutes of moderately intense or 75 minutes of vigorously intense physical activity weekly [26]. Despite these recommendations, a general decline in the level of physical activity was found in studies assessing populations' physical activity during the COVID-19 quarantine particularly in Spain and Poland $[18,20]$. Information on how COVID-19 related quarantine affects physical activity level of population in Saudi Arabia is unidentified.

Limited information is available on the effect quarantine has had on dietary patterns and physical activity before and during the pandemic period. This present study will provide a better understanding of how diet and health in Saudi Arabia has been affected compared to other countries, considering the importance that dietitians can play in such epidemics, and set suitable recommendations for the future. 
The study's aim is to assess the impact of the lockdown on weight changes, dietary intake habits, and physical activity in Saudi Arabia.

\section{Methods}

\section{Study design}

A cross-sectional study was approved by the Unit of the Biomedical Ethics Research Committee at King Abdulaziz University (Jeddah, Saudi Arabia) (reference no. 355-20). All study participants voluntary and anonymously signed an electronic informed consent form prior to their participation.

\section{Sample size calculation}

The Epi Info online sample size calculator [27] was used to compute the required sample size based on both a previous study conducted in Saudi Arabia [28] and the Saudi General Authority for Statistics in 2019 [29]. The anticipated dropout rate was a $20 \%$, with a $99.99 \%$ confidence level, a $5 \%$ margin error, and a design effect of 1 ; therefore, 1,817 participants were required.

\section{Participants and recruitment}

A sample of 2,255 adults from different regions of Saudi Arabia was recruited. The inclusion criteria were citizens and residents of Saudi Arabia age $\geq 18$ years old, either male or female. Participants were asked to fill out an anonymous electronic questionnaire that was created via Google Forms and distributed on various platforms, such as WhatsApp, Twitter, and email. In order to reach out to all society members, the questionnaire link was sent to the authors' relatives, friends, and neighbors to participate in the study and to share the link with their contacts.

\section{The questionnaire}

An online questionnaire was designed to assess and explore changes to dietary habits and physical activity changes during the COVID-19 pandemic in Saudi Arabia. This questionnaire was comprised of four main sections with 27 questions in total and was developed and distributed in Arabic (See Additional file 1 for the English version). Ten experts in the nutrition field reviewed the initial questionnaire and were given a week to submit their comments. Based on their feedback, specific modifications were made and 
amended, such as correcting linguistic errors, rewording some questions, and adding questions to describe changes in the participants' nutritional intake. The survey needed around 5-10 minutes to complete and was made available online for two weeks between June and early July 2020. Participants were informed at the beginning of the questionnaire about the study objective, the confidentiality of collected data, and the estimated time of completion.

The four sections of the questionnaire focused on personal and demographic details, anthropometric measurements, dietary habits and nutritional intake, and physical activity. The first section had eight questions about socio-demographic characteristics, including age, gender, nationality, place of residence, marital status, educational level, monthly house-hold income, and work status.

The second section assessed the participants' anthropometric measurements, including self-reported weight in kilograms and height in centimeters which were used to calculate the body mass index (BMI). Participants were asked about their weight status-whether they had noticed any weight change during quarantine and to estimate the amount of weight gained or lost in kilograms.

The third section evaluated changes in the participants' dietary habits and nutritional intake during quarantine. Participants were asked about the quantities of food they consumed as well as their frequency of snacking, consuming home-cooked food, consuming food from restaurants, and consuming healthy food. In the same section, they were asked about the possible reasons for their change in dietary habits during quarantine. Questions about whether they consumed immune-boosting food items or dietary supplements during quarantine were also included. Participants were also asked about their consumption of the following food items: fruits and vegetables, dairy products, meat, fish, poultry, sweets (cake, chocolate, and ice cream), savory snacks (chips and salty biscuits), sweetened juices and soft drinks, and drinking water. Regarding the food items, participants were asked to choose one of the following choices: increased intake, decreased intake, or no change in the intake.

In the fourth section, participants were asked about changes in their level of physical activity, frequency of physical activity per week, duration of physical activity per day, and types of physical activity performed during quarantine.

\section{Statistical analysis}

A statistical analysis was performed using Minitab® statistical software (Version 19). The AndersonDarling test was used to evaluate variables distribution. Categorical data were expressed as a number and a percentage; continuous data were expressed as mean and standard deviation. Differences between categorical variables were assessed with Chi-square test. A $P$-value of $<0.05$ was statistically significant.

\section{Results}

\section{Characteristics of the study participants}


The survey was completed by 2,255 participants. Table 1 presents the general characteristics of the studied population. Most participants were aged 30-39 years old (24\%), female (64\%), Saudi descent $(91 \%)$, married $(73 \%)$, and from the Western Region of Saudi Arabia (70\%). Although most of the surveyed individuals had a received university-level education (68\%), they showed a high percentage of unemployment (29\%), and the majority had monthly incomes (34\%) of $11,000-20,000$ Saudi riyals. 


\begin{tabular}{|c|c|c|}
\hline Variables & $\mathbf{N}$ & $\%$ \\
\hline \multicolumn{3}{|l|}{ Age (years) } \\
\hline $18-29$ & 484 & 21 \\
\hline $30-39$ & 534 & 24 \\
\hline $40-49$ & 447 & 20 \\
\hline $50-59$ & 469 & 21 \\
\hline$\geq 60$ & 321 & 14 \\
\hline \multicolumn{3}{|l|}{ Gender } \\
\hline Male & 802 & 36 \\
\hline Female & 1,453 & 64 \\
\hline \multicolumn{3}{|l|}{ Nationality } \\
\hline Saudi & 2,058 & 91 \\
\hline Non-Saudi & 197 & 9 \\
\hline \multicolumn{3}{|l|}{ Marital Status } \\
\hline Single & 446 & 20 \\
\hline Married & 1,653 & 73 \\
\hline Divorced & 122 & 5 \\
\hline Widower & 34 & 2 \\
\hline \multicolumn{3}{|l|}{ Region } \\
\hline Western Region & 1,574 & 70 \\
\hline Central Region & 357 & 16 \\
\hline Eastern Region & 190 & 8 \\
\hline Northern Region & 22 & 1 \\
\hline Southern Region & 112 & 5 \\
\hline \multicolumn{3}{|l|}{ Work Status } \\
\hline Student & 229 & 10 \\
\hline Working remotely (from home) & 541 & 24 \\
\hline Working at workplace & 401 & 18 \\
\hline
\end{tabular}




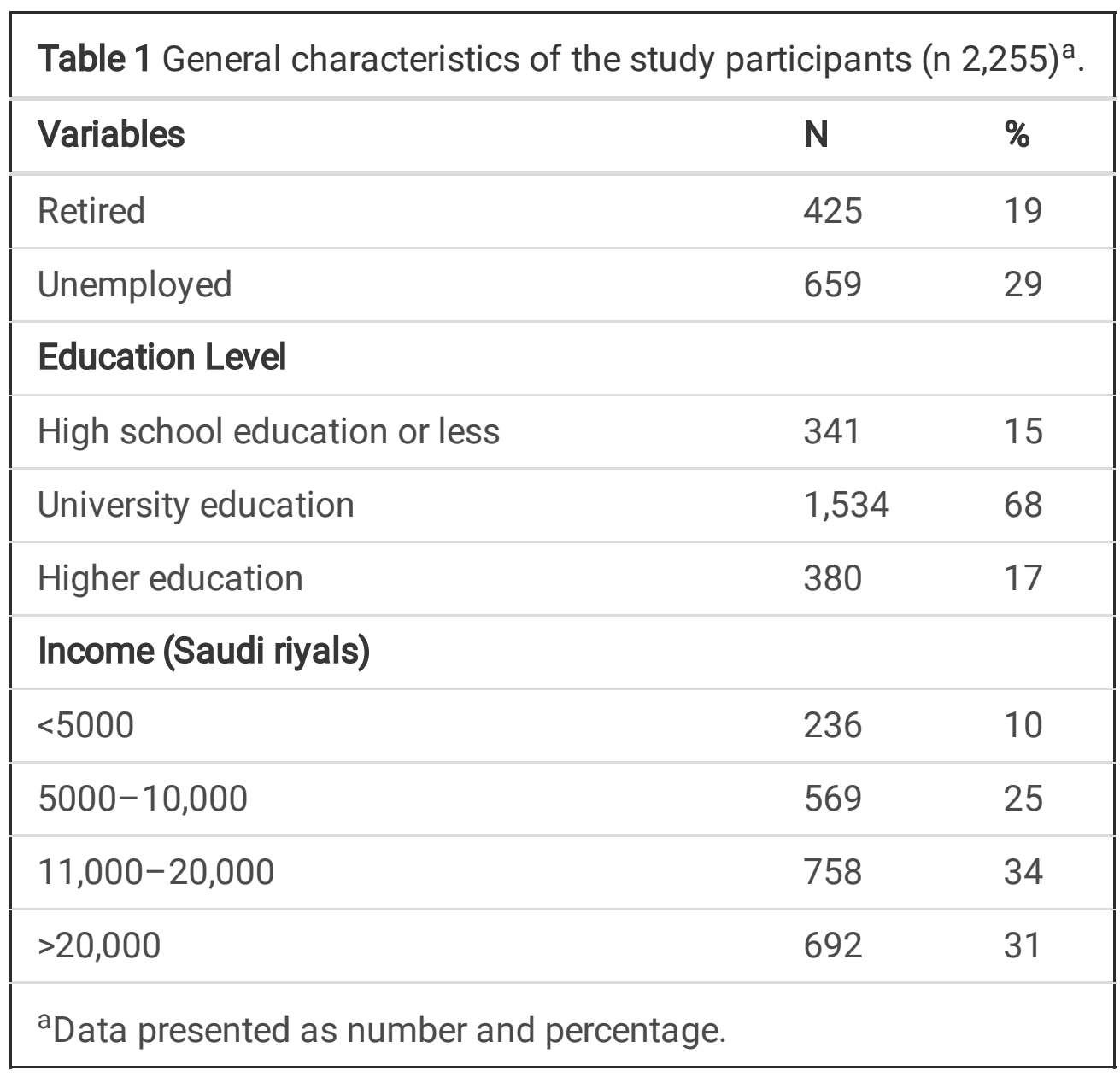

\section{Changes in body weight during the COVID-19 quarantine}

Table 2 presents the participants' BMI and weight changes during quarantine. According to the BMI category, most participants were overweight (36\%), followed by obese and normal weight (31\%). Of those surveyed, $38 \%$ and $26 \%$ reported an increase and decrease of weight, respectively, while $36 \%$ reported no change. Additionally, $34 \%$ reported a $0.0-0.9 \mathrm{~kg}$ weight change during quarantine. 
Table 2 Participants' BMI and weight changes during the COVID-19 quarantine (n 2,255) ${ }^{\text {a }}$.

\begin{tabular}{|lcc|}
\hline Variables & Mean & SD \\
\hline Weight (kg) & 75.6 & N \\
\hline BMI Category & 54 & 2 \\
\hline Underweight & & 31 \\
\hline Normal weight & 691 & 36 \\
\hline Overweight & 803 & 31 \\
\hline Obese & 707 & $\%$ \\
\hline Weight Change & $\mathbf{N}$ & 38 \\
\hline Weight gain & 859 & 26 \\
\hline Weight loss & 582 & 36 \\
\hline No change & 814 & $\%$ \\
\hline Expected Weight Gained or Lost $(\mathbf{k g})$ & $\mathbf{N}$ & 34 \\
\hline $0.0-0.9$ & 773 & 27 \\
\hline $1.0-2.9$ & 594 & 28 \\
\hline $3.0-5.0$ & 638 & 11 \\
\hline$>5.0$ & 250 & \\
\hline SD & & \\
\hline
\end{tabular}

SD, standard deviation; BMI: body mass index.

${ }^{a}$ Data presented as number and percentage unless otherwise stated.

${ }^{b}$ Self-reported weight and height used to calculate the BMI. The BMI categories are underweight (<18.5 kg/m2), normal weight (18.5-24.9 kg/m2), overweight (25.0-29.9 $\mathrm{kg} / \mathrm{m} 2)$, and obese $(\geq 30 \mathrm{~kg} / \mathrm{m} 2)$.

\section{Changes in dietary habits during the COVID-19 quarantine}

Table 3 summarizes the quantity of food consumption and frequency of snacking and eating homecooked, restaurant, or healthy meals in different weight change groups. During quarantine, $40 \%$ of the surveyed participants consumed more food quantities and $45 \%$ snacked between meals more frequently. Increased amount of food consumption (73\%) and the frequency of snacking (63\%) were higher in individuals who gained weight compared to those who reported either losing weight or no weight change 
$(\mathrm{p}<0.001)$. The number of participants who consumed more home-cooked $(73 \%)$ and healthy meals $(47 \%)$ during quarantine was higher than those who consumed more foods from restaurants $(7 \%)$. Consuming more home-cooked meals during quarantine was significantly associated with increased weight gain $(p<0.001)$. A significant difference was seen between the frequency of restaurant food consumption and weight changes during quarantine $(p<0.001)$. During the quarantine, increased consumption of healthy foods was significantly higher in individuals who lost weight compared to those who gained weight or those with no weight change $(p<0.001)$. 
Table 3 Changes in dietary habits compared with weight changes during the COVID-19 quarantine in Saudi Arabia (n 2,255) .

\begin{tabular}{|c|c|c|c|c|c|}
\hline & & Weight $\mathrm{Cr}$ & nge & & \\
\hline & $\begin{array}{l}\text { Total } \\
(n=2,255)\end{array}$ & $\begin{array}{l}\text { Weight } \\
\text { Gain } \\
(n=859)\end{array}$ & $\begin{array}{l}\text { Weight } \\
\text { Loss } \\
(n=582)\end{array}$ & $\begin{array}{l}\text { No } \\
\text { Change } \\
(n=814)\end{array}$ & $\begin{array}{l}P \\
\text { Value }^{\mathrm{b}}\end{array}$ \\
\hline Quantity of Consumed Food & & & & & $<0.001$ \\
\hline Increased & $894(40)$ & $657(73)$ & $62(7)$ & 175 (19) & \\
\hline Decreased & $483(21)$ & $16(3)$ & $371(77)$ & $96(20)$ & \\
\hline No change & $878(39)$ & $186(21)$ & $149(17)$ & $543(62)$ & \\
\hline Frequency of Snacking & & & & & $<0.001$ \\
\hline Increased & $\begin{array}{l}1,022 \\
(45)\end{array}$ & $641(63)$ & $132(13)$ & $249(24)$ & \\
\hline Decreased & $424(19)$ & $36(8)$ & $289(68)$ & $99(23)$ & \\
\hline No change & $809(36)$ & $182(22)$ & $161(20)$ & $466(58)$ & \\
\hline $\begin{array}{l}\text { Frequency of Consuming Home-Cooked } \\
\text { Food }\end{array}$ & & & & & $<0.001$ \\
\hline Increased & $\begin{array}{l}1,637 \\
(73)\end{array}$ & $679(79)$ & $430(74)$ & $528(65)$ & \\
\hline Decreased & $87(4)$ & $23(3)$ & $40(7)$ & $24(3)$ & \\
\hline No change & $531(23)$ & $157(18)$ & $112(19)$ & $262(32)$ & \\
\hline $\begin{array}{l}\text { Frequency of Consuming Food from } \\
\text { Restaurants }\end{array}$ & & & & & $<0.001$ \\
\hline Increased & $154(7)$ & $82(10)$ & $21(3)$ & $51(6)$ & \\
\hline Decreased & $\begin{array}{l}1,802 \\
(80)\end{array}$ & $683(79)$ & $499(86)$ & $620(76)$ & \\
\hline No change & $299(13)$ & $94(11)$ & $62(11)$ & $143(18)$ & \\
\hline Frequency of Consuming Healthy Food & & & & & $<0.001$ \\
\hline Increased & $\begin{array}{l}1,066 \\
(47)\end{array}$ & $300(35)$ & $390(67)$ & $376(46)$ & \\
\hline Decreased & $282(13)$ & $203(24)$ & $28(5)$ & $51(6)$ & \\
\hline No change & $907(40)$ & $356(41)$ & $164(28)$ & $387(48)$ & \\
\hline
\end{tabular}


Table 3 Changes in dietary habits compared with weight changes during the COVID-19 quarantine in Saudi Arabia (n 2,255) .

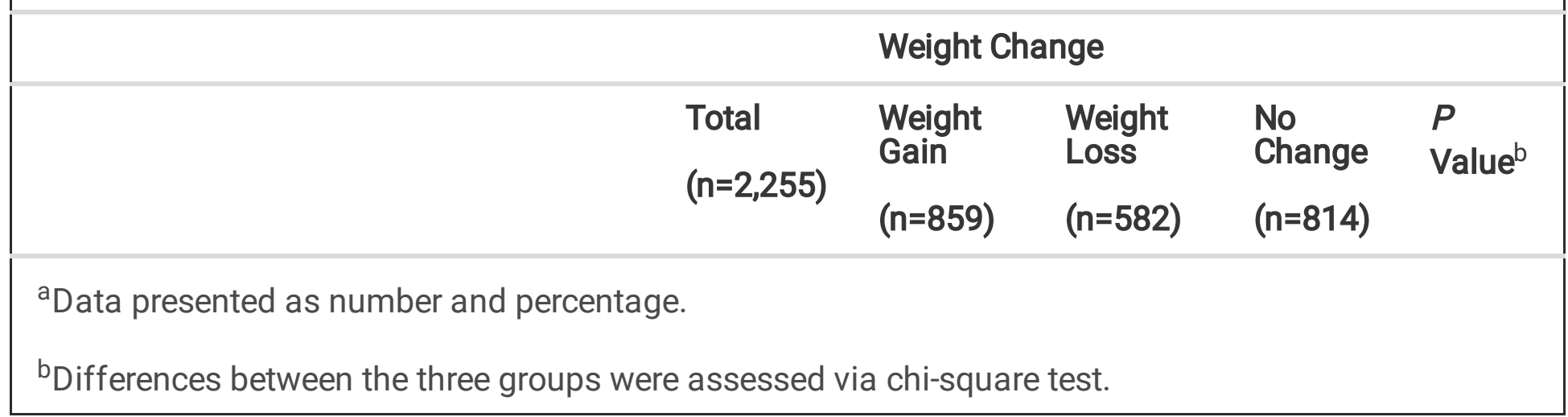

Figure 1 shows some of the reasons behind the changing of dietary habits during quarantine. These changes have been attributed to weight change as a result of social and psychological factors, in addition to lower physical activity and changes in food consumption, as stated before. Feelings of boredom and emptiness ( $n=991,44 \%)$ and the availability of time to prepare meals $(n=905,40 \%)$ were the most reported reasons. The surveyed individuals also reported easy access to new recipes, stress and anxiety, changing sleep patterns, and knowing more about the role of nutrition in boosting immunity as other explanations for changing their dietary habits. Only $9 \%(n=212)$ of participants stated that their quarantine dietary behavior resulted from the inconvenience of food.

\section{Changes in nutritional intake during the COVID-19 quarantine}

The present study also compared changes in the consumption of particular food items during quarantine in relation to the usual intake (Figure 2). While $57 \%$ of participants admitted no changes in their consumption of meats, they did increase their intake of drinking water. There were also similar proportions of surveyed individuals who either increased (48\%) or did not change (43\%) their intake of fruits and vegetables during quarantine. Although $44 \%$ of subjects increased their sweets intake, $46 \%$ did not show any changes in their consumption of sweetened juices and soft drinks.

\section{Immune-boosting foods and dietary supplements}


Half of the participants $(n=1,141,50 \%)$ reported eating immune-boosting foods and $(n=772,34 \%)$ reported consuming dietary supplements during quarantine. In regards to immune-boosting foods, honey (43\%), lemon (40\%), and ginger (32\%), orange (18\%), black seed (17\%), turmeric (16\%), fresh fruits and vegetables (13\%) and garlic (10\%) being the most consumed. Vitamin $\mathrm{C}$ was the most consumed dietary supplement during quarantine $(n=386,50 \%)$, while $22 \%$ and $26 \%$ of participants indicated taking vitamin D and multivitamins, respectively. Other dieary supplements reported include omega-3 (8\%), B vitamins (7\%), iron (6\%), zinc (6\%), calcium (4\%) and magnisium (2\%).

\section{Changes in physical activity level during the COVID-19 quarantine}

Table 4 reports changes in the participants' physical activity during quarantine, which decreased in 1,181 (52\%) subjects, increased in 603 (27\%), and did not change in 471 (21\%). Figure 3 presents the frequency and duration of the participants' physical activity during quarantine. Out of 2,255 participants, 902 (40\%) did not perform any physical activity; $22 \%$ performed physical activity $1-2$ days per week (Figure $3 a$ ). The majority of respondents who exercised $(24 \%)$ reported having one hour of physical activity per day during quarantine (Figure $3 \mathrm{~b}$ ). Thus, decreased levels of physical activity were significantly associated with weight gain $(n=624,73 \%)$ and low weight loss $(n=217,37 \%)$ among these groups $(p<0.001)$ (Table 4$)$.

Table 4 Changes in the level of physical activity compared to weight changes during the COVID-19 quarantine in Saudi Arabia (n 2,255) .

\section{Weight change}

\begin{tabular}{|llllll|} 
Level of Physical Activity & $\begin{array}{c}\text { Total } \\
(\mathbf{n = 2 , 2 5 5 )}\end{array}$ & $\begin{array}{l}\text { Weight Gain } \\
(\mathbf{n = 8 5 9 )}\end{array}$ & $\begin{array}{l}\text { Weight Loss } \\
(\mathbf{n = 5 8 2})\end{array}$ & $\begin{array}{l}\text { No Change } \\
(\mathbf{n = 8 1 4 )}\end{array}$ & $\boldsymbol{P V a l u e}^{\mathrm{b}}$ \\
\hline Increased & $603(27)$ & $122(14)$ & $286(49)$ & $195(24)$ & $<0.001$ \\
\hline Decreased & $1,181(52)$ & $624(73)$ & $217(37)$ & $340(42)$ & \\
\hline No change & $471(21)$ & $113(13)$ & $79(14)$ & $279(34)$ &
\end{tabular}

${ }^{\mathrm{a} D}$ Data presented as number and percentage.

${ }^{b}$ Differences between the three groups were assessed via chi-square test. 
There were different types of physical activities declared by the individuals who performed physical activity during the lockdown $(n=1,415)$. The most common physical activity performed during quarantine was walking (65\%). Other physical activities the participants reported include cardio (11\%) and resistance $(7 \%)$ exercises. Minimal practices of home exercises such as yoga, home training, dancing, Zumba, running, and cycling were also reported.

\section{Discussion}

To the best of our knowledge, this is the first study to evaluate the influence of COVID-19-related home confinement on dietary habits and physical activity in Saudi Arabia. Overall, this study has found that quarantine has negatively affected body weight, dietary habits, and physical activity among the Saudi Arabian population.

The prevalence of obesity and overweightness is increasing dramatically in Saudi Arabia, with a projection rate reaching $59.5 \%$ by 2022 [30]. Data from the current study agrees with this trend, with $67 \%$ of the participants having high BMI levels (> $25 \mathrm{~kg} / \mathrm{m} 2)$. However, other studies from different countries that were conducted during the COVID-19 pandemic have shown that the majority of their participants were within normal BMI range $[18,31]$. This could be explained by the differences in daily routines, lifestyles, and modes of transportation between other countries and Saudi Arabia.

As evident from previous research, during this critical period, obese and overweight individuals could be at greater risk related to the current COVID-19 situation or similar situations in the future compared to individuals with normal weight status. Obese individuals tend to have more breathing difficulties, more intubation complexities, prolonged hospitalization, higher ICU admissions, and higher rate of mortality than other COVID-19 infected groups [32,33]. Obesity is associated with disturbing major functions of the immune system [34]. This, in turn, could leave the person less reactive to vaccines and antivirals, more susceptible to infections, or even cause them to suffer severe complications. Thus, more attention and support should be paid to overweight and obese individuals regarding the positive impact of losing weight on overall health during pandemics, especially in countries with higher rates of obesity, such as Saudi Arabia.

An initial objective of the current study was to identify the effect of a prolonged lockdown on weight changes. As hypothesized, the highest percentage of participants reported weight gain rather than weight loss or no weight change during the lockdown, with a reported weight gain of around $3-5 \mathrm{~kg}$. Similarly, other studies have reported weight gain of $\sim 3-4.5 \mathrm{~kg}$ during quarantine [18]. Since quarantine is associated with limiting people's ability to go to work, the gym, parks, and even practicing normal daily routines, weight gain is expected due to the general decrease in energy expenditure. Moreover, the emotional distress accompanied with being locked at home for months and fear of the novelty and the high spread of COVID-19 [35] might provoke emotional eating and cravings. This result is in line with those of recent studies that captured weight gain concerning COVID-19 home confinement [13, 18, 31]. In this study, however, a comparable percentage of participants did not notice any weight change. This 
could be due to an increased level of awareness, or they may have not been as majorly affected by quarantine as people who continued to go to their workplaces during the curfew in comparison to the weight gain group.

The present study has demonstrated similar percentages between people who admitted an increase in the consumption of food in general and those who did not report any changes in the amount of food consumed during quarantine. When it comes to snacking between meals, however, almost half of the participants admitted an increase in frequency since the start of quarantine. In regard to weight changes, weight gain was associated with increased amounts and frequency of meals and snacks. These findings support previous research, which links the current global lockdown with higher amounts of food intake $[18,19,31,36]$. A logical explanation is the nature of quarantine, with people spending most of the day locked at homes with minimal activities available, watching more television and having an abundance of stocked groceries. Prior evidence has shown that the availability of large food quantities for many days might lead to overeating, not necessarily due to hunger [37]. During home confinement periods, people tended to stock their kitchens with different foods to reduce unnecessary grocery trips due to the fear of contracting the infection [18]. The majority of these foods are ready-to-eat meals, canned foods, and products with long-shelf-life, which are often dense with calories.

Cooking at home is usually perceived as healthier or at least lower in calories than eating from restaurants. Surprisingly, almost $80 \%$ of participants in this study who gained weight also reported a significant increase in their home-cooked meals than before the lockdown. This result might be elaborated by the fact that not all cooking methods are considered healthy; some people might add large amounts of fat and/or sugar, which could lead to a substantial amount of added calories. Although such ingredients are high in calories, they play a role in increasing the palatability of food, making it more appealing in such stressful situations. Interestingly, it was found by Rodríguez-Pérez et al. [20] that people in Spain have increased their Google searches of the term "homemade cake" since the start of the lockdown. Homemade bread and cakes intake were also found to be higher during quarantine in Italy [19, 31]; therefore, a similar trend in food and cooking could possibly be applied in Saudi Arabia. However, a significant increase in home-cooked meals was also shown in $74 \%$ of the group who lost weight, which is apparently due to a healthier and less caloric way of cooking. This finding is consistent with that of Rodriguez-Perez et al. [20] who found a better adherence to healthy types of cooking during the COVID-19 quarantine among the Spanish population.

The main two reasons indicated in the study sample for changing dietary habits during the quarantine were more due to boredom and emptiness or having more time for meals preparation. Staying home for long periods may raise the feeling of boredom, which is often associated with overeating to escape monotony [38]. This behavior was also reported by Zachary et al. [13].

In this study, participants were also asked if their overall intake of healthy foods had changed compared to before quarantine. Almost half of the participants declared an increased intake of healthy food; however, the definition "healthy food" was not stated in the question and was thus dependent on the 
perception of each individual. Expectedly, two-thirds of the participants, who were in the weight loss group, expressed an increase in healthy food consumption. The same group has reported, as mentioned previously, a notable increase in home cooking.

The current study also inspected changes in the intake of particular foods during the lockdown. Unexpectedly, higher water intake was reported by more than half of the participants. This is a positive behavior for the Saudi population, as hydration status has been linked to innate mucosal immunity [39]. This behavior might because of easier access to water and increased awareness of the amount of water consumption during quarantine. An Italian study also showed a sufficient water drinking habit among the Italian population [31]. Similar to the findings of other studies [18, 19, 31], however, the majority of subjects in the present study have shown an increased intake of sweets, including cakes, chocolate, and ice cream. This also accords with this study's observation of dietary patterns, which showed that subjects in this study increased their snacking frequency during quarantine; thus, it can be assumed that the bulk of snacks consumed were sugary ones rather than savory. During confinement, people were facing incredibly stressful conditions, between continuously reading or watching updates in the news and being afraid to get infected with the COVID-19. Subsequently, stress can urge people to have food cravings, especially to sweets known as "comfort food," which are loaded with calories. Craving for carbohydrates, in particular, stimulates the production of serotonin (a neurotransmitter found in the brain), which positively affects mood [40]. Such behavior, in turn, could make people at a higher risk for obesity and serious COVID-19 complications. In the current study, almost half of the subjects increased their fruit and vegetable consumption. This is noteworthy, particularly in a society that relies on an omnivorous diet that is rich in red meat and poor in fruits and vegetables, as discussed by Afshin et al. [41]. However, this may not help with avoiding the potential risk of low vitamin and mineral levels and the susceptibility to chronic and infectious diseases in the Saudi population, as only a small percentage have met these dietary recommendations while the majority have poor dietary practices during regular days [42]. Therefore, nutrition professionals in Saudi Arabia should pay further attention to increase awareness regarding the importance of adopting healthier diets that have higher intake of fruits, vegetables, and other antiinflammatory components, such as olive oil (the Mediterranean diet), especially in stressful conditions like in the COVID-19 pandemic. Recently, the Mediterranean diet has been recommended to be followed during COVID-19 quarantine owing to the role it plays in strengthening the immunity [17]. Regarding the intake of fruits and vegetables during quarantine in other studies, findings were inconsistent. The intake of fruits and vegetables were increased in Spain [20], decreased in Poland [18], and did not changed in Italy [31].

Since there is still no vaccine or treatment to cure COVID-19, the main reliance is on the power and capability of the immune system to protect us from the virus. The study revealed that the most commonly consumed natural food during quarantine was honey, followed by lemon. As mentioned before, consuming honey is part of Saudi culture; furthermore, honey is known for its general potent antiviral effects by many researchers [43-45]. Some efforts have been conducted in Saudi Arabia to examine the effect of honey and other natural products on COVID-19 patients [21]. However, further research is needed. 
At this point, there is still no strong evidence to support using dietary supplementation to prevent or treat COVID-19. However, some vitamins and minerals might have some positive effects in relation to COVID$19[46,47]$. In the current study, half of the participants who admitted to taking dietary supplements reported that they were taking vitamin $C$ supplements, while a quarter reported the intake of multivitamins and vitamin D. It is unsurprising that vitamin $C$ was the most consumed dietary supplement, as it is well known for its immune-boosting effects, especially in individuals with subnormal levels of the vitamin, as stated by Carr et al. [48].

A general decline in the level of physical activity was found in this study. This was in line with previous studies that assessed physical activity during quarantine among different populations $[18,20]$. In the present study, approximately half of the population reported not practicing any kind of physical activity; however, the other half reported performing 60-120 minutes per week of moderate intensity exercise (predominantly walking indoors or outdoors), which is still less than the recommended level of physical activity to provide protective effects against chronic diseases [49]. Expectedly, lower levels of physical activity were associated with weight gain, while increased levels were associated with losing weight. This study supports recent evidence from an international observation showing a universal decline in all physical activity levels during COVID-19 pandemic [36]. More efforts should be paid regarding educating Saudi adults about the importance of physical activity even with minimal practices, which might increase energy expenditure and promote neuromuscular, cardiovascular, and metabolic health [50]. Moreover, the government should help increase motivation and exposure to alternative activities that could be practiced from home, such as using videos or virtual online classes designed for different age groups.

The study was done in a relatively short period of time as suggested by previous studies [7]. It also took place amid the pandemic's highest restrictions imposed in Saudi Arabia, a G20 country that is part of the Middle East and shares many cultural, habitual, and dietary behaviors that can also provide insights into neighboring countries. To the best of the authors' knowledge, this is the first study to provide the previously mentioned insights in Saudi Arabia. Although this study might be specific to certain circumstances, the outcomes and results are significant in the prevention and preparation of any future incidents that necessitates a lockdown.

Although this study provides a general insight on how dietary habits and physical activity changed during the pandemic, it has some limitations. Many considerations were put in mind when structuring the questionnaire to encourage all societal groups to participate. Although the questionnaire was relatively short and used simple language, it was limited in providing specific information, such as the exact quantities of food consumed and details about food preparation methods. It is also evident that this study used self-reported information, including weight and height measurements and expected weight changes during quarantine due to its anonymous nature, and thus might introduce misreported data. Although data were collected from all regions of Saudi Arabia, the variations in dietary habits and lifestyle between these regions were not considered. However, the aim of this study focused on the overall dietary habits and physical activity changes in the whole country. 


\section{Conclusion}

The present study is the first to provide data regarding dietary habits and physical activity during the COVID-19 home confinement period in Saudi Arabia. The majority of the population have shown weight gain, increased food consumption, and decreased physical activity. In particular, subjects who gained weight tended to consume more snacks, larger food quantities, and showed lower physical activity levels. A trend toward healthier food intake compared to regular diets was seen, including increased intake of fruits, vegetables, and water and decreased intake of sweetened juices and soft drinks. The intake of meats and sweets, meanwhile, either increased or did not modify in most subjects. Assessing the changes in populations' dietary habits during the lockdown may help with understanding the implications surrounding the population's health and wellbeing later in life. For that reason, further larger-scale studies should be undertaken to investigate if the COVID-19 lockdown would result in a persistent effect on dietary habits and physical activity.

\section{Abbreviations}

SARS-CoV-2: SARS Coronavirus 2; WHO: world health organization; BMI: body mass index

\section{Declarations}

\section{Acknowledgments}

The authors would like to thank all the study participants for their participation in this study. The authors thank Dena Khawandanah for her assistance in manuscript writing.

\section{Authors' contributions}

MAB and JK designed the study. RKN analysed the data. SA interpreted the results. MAB, JK and SA wrote the original manuscript. RKN and SA reviewed and edited the manuscript. All authors have read and agreed to the published version of the manuscript. All authors have read and agreed to the published version of the manuscript.

\section{Funding}

This research received no external funding.

\section{Availability of data and materials}

The datasets used and/or analysed during the current study are available from the corresponding author on reasonable request

\section{Ethics approval and consent to participate}


The study was approved by the Unit of the Biomedical Ethics Research Committee at King Abdulaziz University (Jeddah, Saudi Arabia) (reference no. 355-20). All study participants voluntary and anonymously signed an electronic informed consent form prior to their participation.

\section{Consent for publication}

Not applicable.

\section{Competing interests}

The authors declare that they have no competing interests.

\section{References}

1. Centers for Disease Control and Prevention. Coronavirus (COVID-19). 2020. https://www.cdc.gov/coronavirus/2019-ncov/index.html. Accessed 25 Jul 2020.

2. Jiang S, Xia S, Ying T, Lu L. A novel coronavirus (2019-nCoV) causing pneumonia-associated respiratory syndrome. Cell Mol Immunol. 2020;17:554. doi:10.1038/s41423-020-0372-4.

3. Burki T. Outbreak of coronavirus disease 2019. Lancet Infect Dis. 2020;20:292-3. doi:10.1016/S1473-3099(20)30076-1.

4. Cucinotta D, Vanelli M. WHO declares COVID-19 a pandemic. Acta Biomed. 2020;91:157-60. doi:10.23750/abm.v91i1.9397.

5. Sohrabi C, Alsafi Z, O'Neill N, Khan M, Kerwan A, Al-Jabir A, et al. World Health Organization declares global emergency: A review of the 2019 novel coronavirus (COVID-19). Int J Surg. 2020;76:71-6.

6. World Health Organization. Coronavirus disease (COVID-2019) situation reports. 2020. https://www.who.int/emergencies/diseases/novel-coronavirus-2019/situation-reports. Accessed 28 Jul 2020.

7. Geldsetzer P. Use of Rapid Online Surveys to Assess People's Perceptions During Infectious Disease Outbreaks: A Cross-sectional Survey on COVID-19. J Med Internet Res. 2020;22:e18790.

8. Dandekar R, Barbastathis G. Neural Network aided quarantine control model estimation of global Covid-19 spread. arXiv Prepr arXiv. 2020;:1-13.

9. Ministry of Health. Media Center. 2020. https://www.moh.gov.sa/en/Ministry/MediaCenter/Pages/default.aspx. Accessed 28 Jul 2020.

10. Komies S, Aldhahir AM, Almehmadi M, Alghamdi SM, Alqarni A, Oyelade T, et al. COVID-19 Outcomes in Saudi Arabia and the UK: A Tale of Two Kingdoms. medRxiv. 2020;:1-19.

11. Ministry of Health. MOH News. 2020. https://www.moh.gov.sa/en/Ministry/MediaCenter/News/Pages/News-2020-07-27-004.aspx. Accessed 27 Jul 2020.

12. Mesa Vieira C, Franco OH, Gómez Restrepo C, Abel T. COVID-19: The forgotten priorities of the pandemic. Maturitas. 2020;136:38-41. 
13. Zachary Z, Brianna F, Brianna L, Garrett P, Jade W, Alyssa D, et al. Self-quarantine and weight gain related risk factors during the COVID-19 pandemic. Obes Res Clin Pract. 2020;14:210-6.

14. Bhutani S, Cooper JA. COVID-19 related home confinement in adults: weight gain risks and opportunities. Obesity. 2020;28:1576-7.

15. Abbas AM, Kamel MM. Dietary habits in adults during quarantine in the context of COVID-19 pandemic. Obes Med. 2020;19 January:100254.

16. Naja F, Hamadeh R. Nutrition amid the COVID-19 pandemic: a multi-level framework for action. Eur J Clin Nutr. 2020;74:1117-21.

17. Muscogiuri G, Barrea L, Savastano S, Colao A. Nutritional recommendations for CoVID-19 quarantine. Eur J Clin Nutr. 2020;74:850-1.

18. Sidor A, Rzymski P. Dietary Choices and Habits during COVID-19 Lockdown: Experience from Poland. Nutrients. 2020;12:1657.

19. Scarmozzino F, Visioli F. Covid-19 and the Subsequent Lockdown Modified Dietary Habits of Almost Half the Population in an Italian Sample. Foods. 2020;9:675.

20. Rodríguez-Pérez C, Molina-Montes E, Verardo V, Artacho R, García-Villanova B, Guerra-Hernández EJ, et al. Changes in Dietary Behaviours during the COVID-19 Outbreak Confinement in the Spanish COVIDiet Study. Nutrients. 2020;12:1730.

21. Sayed SM El, Almaramhy HH, Aljehani YT, Okashah AM, El-Anzi ME, AlHarbi MB, et al. The EvidenceBased TaibUVID Nutritional Treatment for Minimizing COVID-19 Fatalities and Morbidity and eradicating COVID-19 pandemic: A novel Approach for Better Outcomes (A Treatment Protocol). Am J Public Heal Res. 2020;8:54-60.

22. Alqahtani BA, Alenazi AM, Alhowimel AS, Elnaggar RK. The descriptive pattern of physical activity in Saudi Arabia: analysis of national survey data. Int Health. 2020;:1-8.

23. Panahi S, Tremblay A. Sedentariness and Health: Is Sedentary Behavior More Than Just Physical Inactivity? Front Public Heal. 2018;6 September:1-7.

24. Butler MJ, Barrientos RM. The impact of nutrition on COVID-19 susceptibility and long-term consequences. Brain Behav Immun. 2020;87 January:53-4.

25. Abbas AM, Fathy SK, Fawzy AT, Salem AS, Shawky MS. The mutual effects of COVID-19 and obesity. Obes Med. 2020;19 January:100250.

26. World Health Organization. How to stay physically active during COVID-19 self-quarantine. 2020. https://www.euro.who.int/en/health-topics/disease-prevention/physicalactivity/news/news/2020/3/how-to-stay-physically-active-during-covid-19-self-quarantine. Accessed 25 Jul 2020.

27. Centers for Disease Control and Prevention. Division of Health Informatics and Surveillance (DHIS). 2018. https://www.cdc.gov/csels/divisions/dhis/index.html. Accessed 5 Jun 2020.

28. Alkhaldy AA, Taha DS, Alsahafi SE, Naaman RK, Alkhalaf MM. Response of the public and restaurant owners to the mandatory menu energy-labelling implementation in restaurants in Saudi Arabia. 
Public Health Nutr. 2020;:1-13.

29. General Authority for Statistics Kingdom of Saudi Arabia. 2019.

https://www.stats.gov.sa/sites/default/files/population_by_age_groups_and_gender_en.pdf. Accessed 6 Jun 2020.

30. Al-Quwaidhi A., Pearce M. Trends and future projections of the prevalence of adult obesity in Saudi Arabia, 1992-2022. East Mediterr Heal J. 2014;20:184-91.

31. Di Renzo L, Gualtieri P, Pivari F, Soldati L, Attinà A, Cinelli G, et al. Eating habits and lifestyle changes during COVID-19 lockdown: an Italian survey. J Transl Med. 2020;18:229.

32. Simonnet A, Chetboun M, Poissy J, Raverdy V, Noulette J, Duhamel A, et al. High Prevalence of Obesity in Severe Acute Respiratory Syndrome Coronavirus-2 (SARS-CoV-2) Requiring Invasive Mechanical Ventilation. Obesity. 2020;28:1195-9.

33. Kalligeros M, Shehadeh F, Mylona EK, Benitez G, Beckwith CG, Chan PA, et al. Association of Obesity with Disease Severity Among Patients with Coronavirus Disease 2019. Obesity. 2020;28:1200-4.

34. Milner JJ, Beck MA. Micronutrients, immunology and inflammation The impact of obesity on the immune response to infection. Proc Nutr Soc. 2012;71:298-306.

35. Lima CKT, Carvalho PM de M, Lima I de AAS, Nunes JVA de O, Saraiva JS, de Souza RI, et al. The emotional impact of Coronavirus 2019-nCoV (new Coronavirus disease). Psychiatry Res. 2020;287 January:112915.

36. Ammar A, Brach M, Trabelsi K, Chtourou H, Boukhris O, Masmoudi L, et al. Effects of COVID-19 Home Confinement on Eating Behaviour and Physical Activity: Results of the ECLB-COVID19 International Online Survey. Nutrients. 2020;12:1583.

37. Rolls BJ, Roe LS, Meengs JS. The Effect of Large Portion Sizes on Energy Intake Is Sustained for 11 Days. Obesity. 2007;15:1535-43.

38. Havermans RC, Vancleef L, Kalamatianos A, Nederkoorn C. Eating and inflicting pain out of boredom. Appetite. 2015;85:52-7.

39. Fortes MB, Diment BC, Di Felice U, Walsh NP. Dehydration decreases saliva antimicrobial proteins important for mucosal immunity. Appl Physiol Nutr Metab. 2012;37:850-9.

40. Rodríguez-Martín BC, Meule A. Food craving: new contributions on its assessment, moderators, and consequences. Front Psychol. 2015;6:45-55.

41. Afshin A, Micha R, Khatibzadeh S, Fahimi S, Shi P, Powles J, et al. The impact of dietary habits and metabolic risk factors on cardiovascular and diabetes mortality in countries of the Middle East and North Africa in 2010: a comparative risk assessment analysis. BMJ Open. 2015;5:e006385e006385.

42. Moradi-Lakeh M, El Bcheraoui C, Afshin A, Daoud F, AlMazroa MA, Al Saeedi M, et al. Diet in Saudi Arabia: findings from a nationally representative survey. Public Health Nutr. 2017;20:1075-81.

43. Viuda-Martos M, Ruiz-Navajas Y, Fernández-López J, Pérez-Álvarez JA. Functional Properties of Honey, Propolis, and Royal Jelly. J Food Sci. 2008;73:R117-24. 
44. Watanabe K, Rahmasari R, Matsunaga A, Haruyama T, Kobayashi N. Anti-influenza Viral Effects of Honey In Vitro: Potent High Activity of Manuka Honey. Arch Med Res. 2014;45:359-65.

45. Yao L, Jiang Y, D’Arcy B, Singanusong R, Datta N, Caffin N, et al. Quantitative High-Performance Liquid Chromatography Analyses of Flavonoids in Australian Eucalyptus Honeys. J Agric Food Chem. 2004;52:210-4.

46. Cheng RZ. Can early and high intravenous dose of vitamin C prevent and treat coronavirus disease 2019 (COVID-19)? Med Drug Discov. 2020;5 January:100028.

47. Grant WB, Lahore H, MCDonnell SL, Baggerly CA, French CB, Aliano JL, et al. Evidence that Vitamin D Supplementation Could Reduce Risk of Influenza and COVID-19 Infections and Deaths. Nutrients. 2020;12:988.

48. Carr A, Maggini S. Vitamin C and Immune Function. Nutrients. 2017;9:1211.

49. Lippi G, Henry BM, Bovo C, Sanchis-Gomar F. Health risks and potential remedies during prolonged lockdowns for coronavirus disease 2019 (COVID-19). Diagnosis. 2020;7:85-90.

50. Narici M, Vito G De, Franchi M, Paoli A, Marcolin G, Grassi B, et al. Impact of sedentarism due to the COVID-19 home confinement on neuromuscular, cardiovascular and metabolic health: Physiological and pathophysiological implications and recommendations for physical and nutritional countermeasures. Eur J Sport Sci. 2020;0:1-22.

\section{Figures}

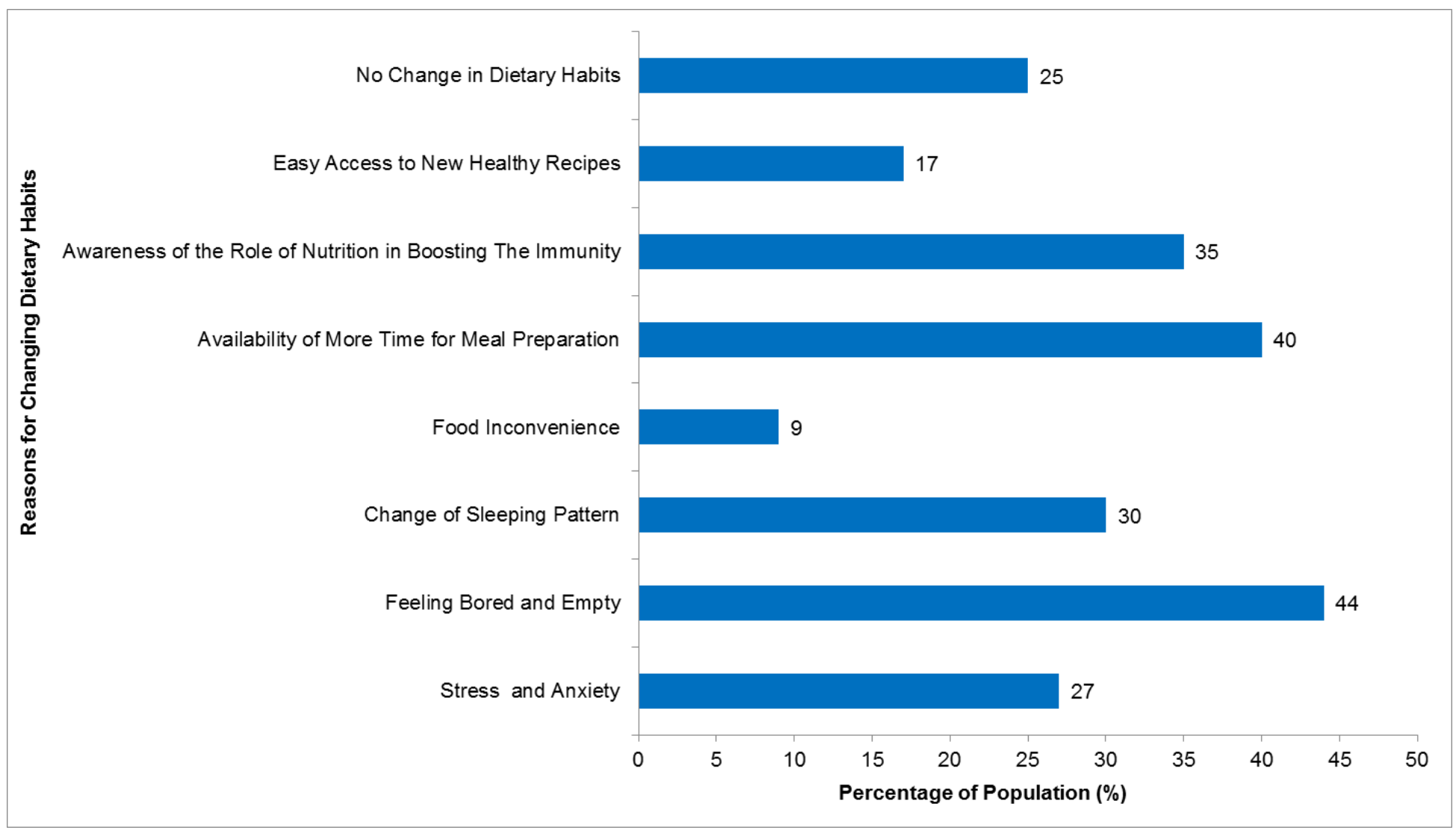


Figure 1

Reasons reported by the Saudi Arabian population for changing their dietary habits during the COVID-19 quarantine (n 2,255).

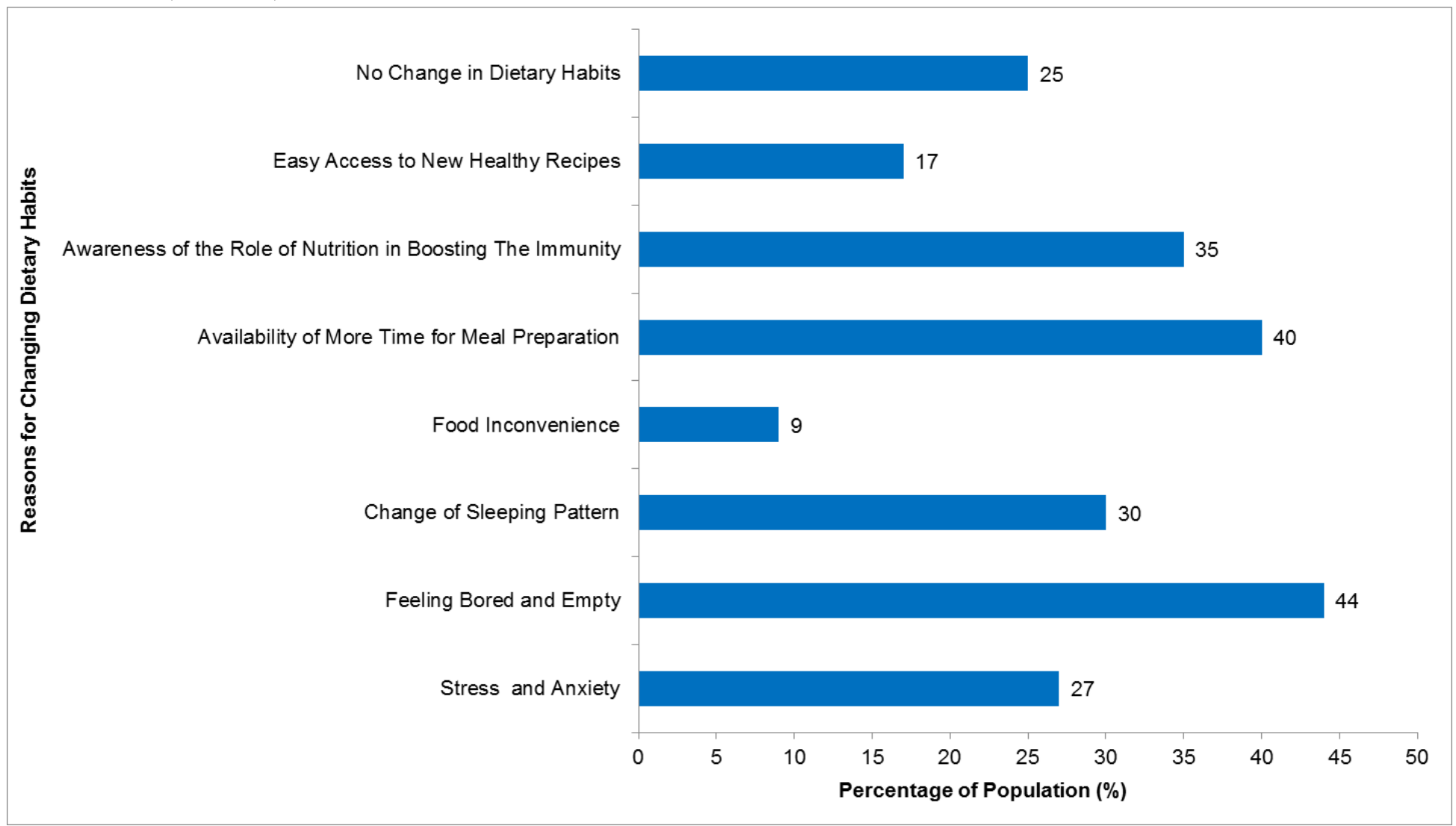

\section{Figure 1}

Reasons reported by the Saudi Arabian population for changing their dietary habits during the COVID-19 quarantine (n 2,255). 


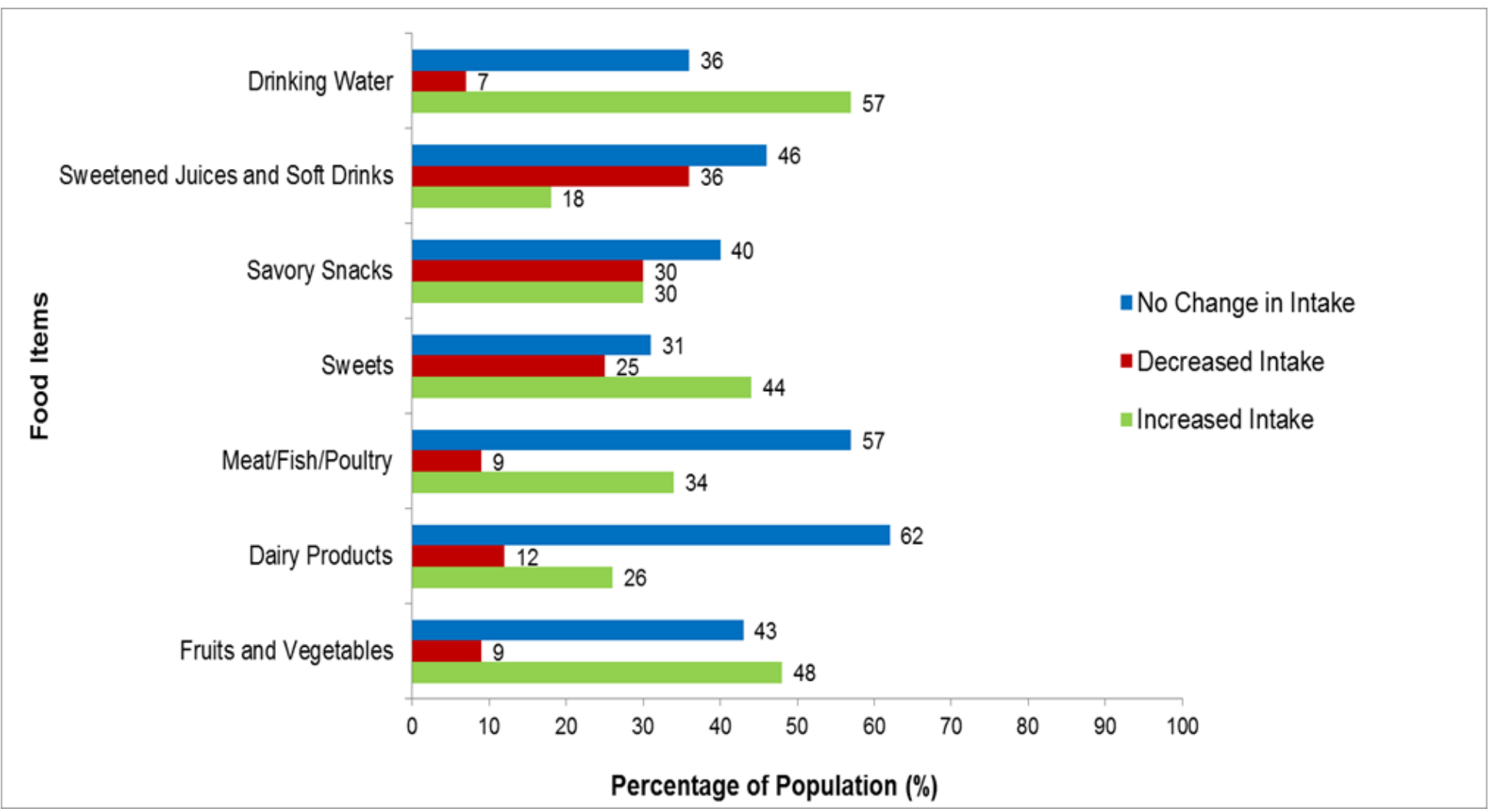

\section{Figure 2}

Changes in the consumption of particular food items during the COVID-19 quarantine period compared with the usual intake (n 2,255).

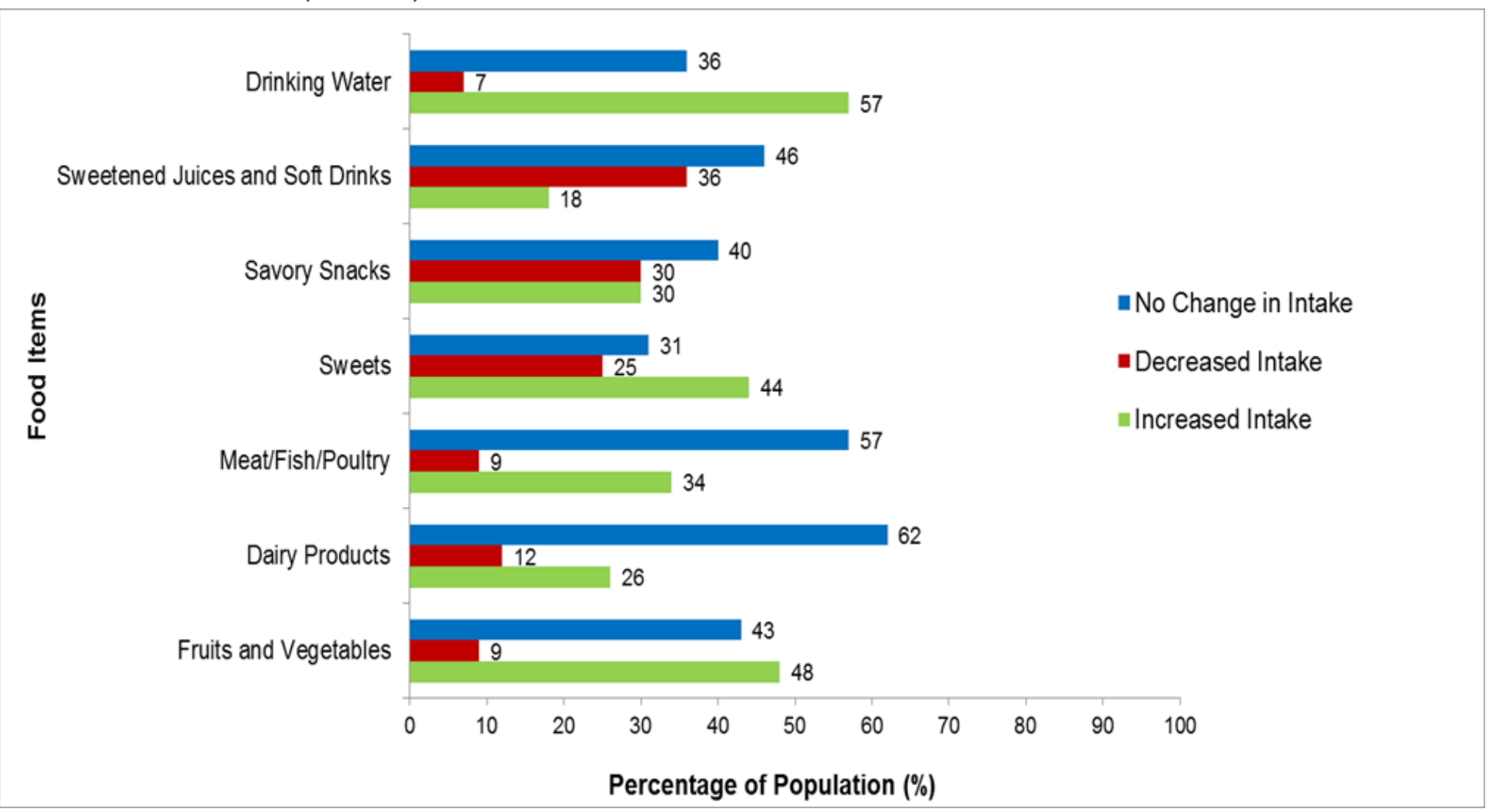

Figure 2 
Changes in the consumption of particular food items during the COVID-19 quarantine period compared with the usual intake (n 2,255).

A



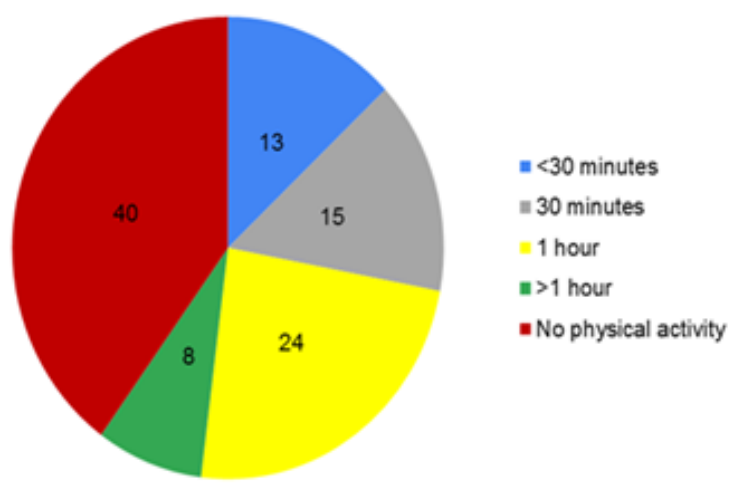

\section{Figure 3}

$=1-2$ days

$=3$ days

4-6 days

nDaily

- No physical activity

\section{B}

Frequency of physical activity per week (a) and duration per day (b) during the COVID-19 quarantine (n 2,255). 
A

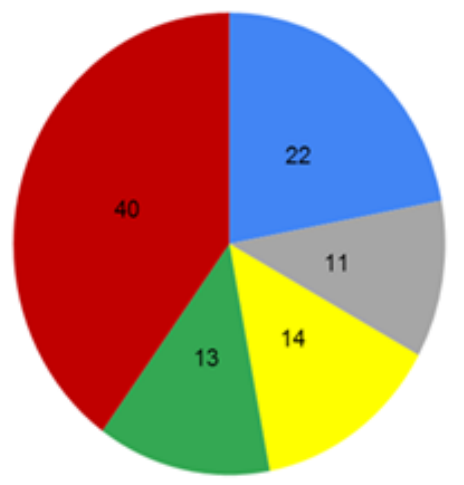

B



\section{Figure 3}

$=1-2$ days

$=3$ days

4-6 days

m Daily

- No physical activity

$$
1 \text { hour }
$$

$>1$ hour

-

\section{-}

Frequency of physical activity per week (a) and duration per day (b) during the COVID-19 quarantine ( $\mathrm{n}$ 2,255).

\section{Supplementary Files}

This is a list of supplementary files associated with this preprint. Click to download.

- Additionalfile1.docx

- Additionalfile1.docx 